\title{
Hearing outcome between stapes graft assembly and stapes cartilage graft assembly in chronic otitis media active squamous disease
}

\author{
Anuj Shah", ${ }^{1, *}$ Rupa Parikh², Vikram Patel ${ }^{3}$ \\ ${ }^{1}$ Senior Resident, ${ }^{2}$ Professor \& HOD, ${ }^{3}$ Assistant Professor, Dept. of ENT, ${ }^{1,3}$ GMERS Medical College, Vasad, Gujarat, ${ }^{2}$ Surat \\ Muncipal Institute of Medical Education and Research, Surat, Gujarat, India
}

*Corresponding Author:

Email: anujshah.1989@gmail.com

\begin{abstract}
Introduction: The cholesteatoma is a sac lined by keratinizing stratified squamous epithelium in the middle ear cleft with continuous desquamated epithelium arranged like onion skin layers. It is also known as the non-malignant bone destroying disease of the middle ear cleft. Our study aims to compare the hearing outcome in these active sqamosal cases after doing stapescartilage-graft assembly and stapes-graft assembly in patients undergoing reconstruction in canal wall down mastoidectomy with type III tympanoplasty.

Materials and Method: Total number of 50 patients with chronic otitis media active squamous disease, who had undergone different types of ossicular chain reconstruction by type III tympnoplasty with canal wall down mastoidectomy between January 2017 and September 2017, were enrolled in the study. Post-operative hearing gain were evaluated by pure tone audiometry at 6 months after surgery.

Results: In terms of air-bone gap, stapes cartilage graft assembly patients have more improvement in hearing than patients with stapes graft assembly. We found 11.2 DB improvement with stapes-cartilage-graft assembly as compared to 5.76 DB in stapesgraft assembly.

Conclusion: Canal wall down mastoidectomy with type III tympnoplasty, stapes-cartilage-graft assembly technique have more hearing improvement than stapes graft assembly technique.
\end{abstract}

Keywords: Chronic Otitis Media active squamosal type, Mastoidectomy, Stapes-Cartilage-Graft Assembly, Stapes Graft Assembly.

\section{Introduction}

Chronic Otitis Media squamous disease, previously known as the attico-antral type usually presents with marginal perforation having cholesteatoma which is the hallmark of this condition and also considered as the complication producing element. ${ }^{1,2}$ The cholesteatoma is a sac lined by keratinizing stratified squamous epithelium in the middle ear cleft with continuous desquamated epithelium arranged like onion skin layers. It is also known as the non-malignant bone destroying disease of the middle ear cleft. ${ }^{3}$

Canal wall down (CWD) and canal wall up (CWU) mastoidectomy represent two surgical methods to middle ear cleft pathology. Canal wall down mastoidectomy with tympanoplasty which has lower rates of recurrence and fewer surgical procedures are needed. Canal wall up mastoidectomy with tympanoplasty does not require substantial anatomical modifications, require less postoperative care but has higher rates of recurrence or residual disease. ${ }^{4}$

This study was undertaken to compare the hearing outcome in Stapes-Graft assembly and StapesCartilage-Graft assembly for ossicular chain reconstruction after CWD mastoidectomy.

\section{Materials and Method}

The present study was a retrospective longitudinal observational study carried out at the Department of ENT \& Head \& Neck Surgery in our institute for a duration of 9 months, from January 2017 to September 2017.

Patients with chronic otitis media active squamous disease involving the middle ear and mastoid who needed a canal wall down mastoidectomy with tympanoplasty were considered for this study.

Patients with poor cochlear reserve or history of trauma to the ear or temporal bone or those suffering from complications of otitis media were excluded from this study. Patients who were advised revision surgery also not considered as also those who refused to participate in this study.

50 patients with squamosal chronic otitis media, undergoing canal wall down mastoidectomy with tympanoplasty, who came for regular follow- up were included in this study. Out of the cases studied 28 were male and 22 were female.

Twenty five patients underwent type III tympanoplasty with stapes graft assembly technique. Rest twenty five patients had type III tympanoplasty with stapes cartilage graft assembly technique.In these patients cartilages were harvested from tragal cartilage. Adequate size of meatoplasty was performed routinely in all cases.

Objective assessment of hearing improvement was done at sixth post-operative month. Postoperative hearing assessment was documented by performing pure tone audiometry on each postoperative follow-up. A digital audiometer was used in all the cases. Air-bone 
gap was calculated from air conduction and bone conduction thresholds of pure tone audiometry at 500 $\mathrm{Hz}, 1000 \mathrm{~Hz}, 2000 \mathrm{~Hz} \& 4000 \mathrm{~Hz}$ determined at each follow-up. Postoperative hearing gain was calculated from pure tone audiometry before the operation and 6 months of the follow up examination. Mean differences in threshold were calculated for air and bone conduction or air-bone gap (ABG).

\section{Statistical analysis}

Statistical analysis was performed by using paired $\mathrm{t}$ test.

\section{Results}

In this study total numbers of 50 patients were selected. The male: female ratio was $1.2: 1$. The patients mostly belonged to low socioeconomic status. In 20 patients disease was in left ear, in 23 patients it was in right ear and in 7 patients it was bilateral.

Amongst the findings of tympanic membrane, In 21 patients it was postero-superior quadrant (PSQ) cholesteatoma, in 23 patients it was attic cholesteatoma and in 6 patients it was both attic \& PSQ type. Ear discharge was the presenting symptom in most of the patients. Cholesteatoma was the most common pathology found amongst the operated ears (76.7\%). While both cholesteatoma and granulations were seen in $16.7 \%$ of the cases. Rest patients had granulation tissue alone.

The average of air conduction and bone conduction thresholds, both preoperatively and postoperatively, along with air-bone gap were calculated. (Table I and Fig. 1)

Table I: Pre-op and post-op hearing levels of both the groups

\begin{tabular}{|c|c|c|}
\hline \multicolumn{3}{|c|}{$\begin{array}{l}\text { Air conduction pure tone average (AC PTA), bo } \\
\text { conduction pure tone average (BC PTA), air bone gap (AB } \\
\text { and ABG gain before and } 6 \text { months after surgery in } \mathrm{dB} \\
\text { Group A: Stapes Temporalis fascia graft (TFG) assembly } \\
\text { Group B: stapes Cartilage Graft assembly }\end{array}$} \\
\hline & Group A & Group B \\
\hline AC PTA pre-op & 48.83 & 48 \\
\hline AC PTA post-op & 48.9 & 38.83 \\
\hline BC PTA pre-op & 9.08 & 7.16 \\
\hline BC PTA post-op & 16.58 & 11.36 \\
\hline ABG pre-op & 39.74 & 45 \\
\hline ABG post-op & 32.31 & 27.46 \\
\hline ABG Gain & 7.43 & 17.53 \\
\hline
\end{tabular}

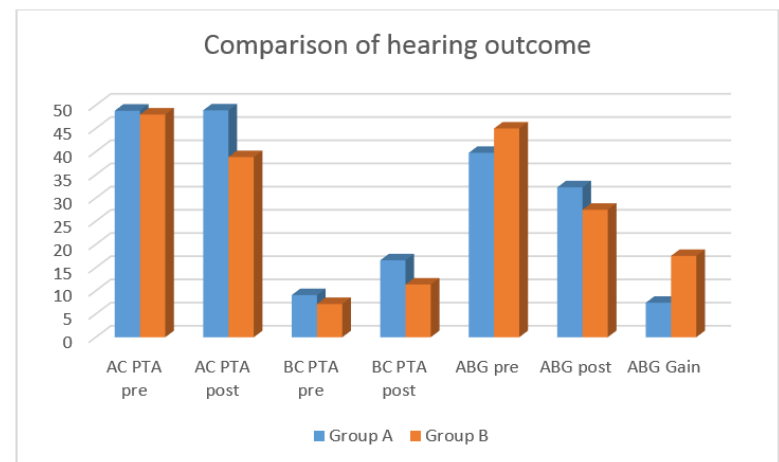

Fig. 1: Pre and post operative data on the hearing status of both the groups

We found significant statistical outcome after comparing both the groups and so stapes-cartilage-graft assembly is far more superior than only stapes-graft assembly. (Table II)

Table II: Hearing gain comparison

\begin{tabular}{|l|l|c|c|c|c|}
\hline & & $\begin{array}{c}\text { Pre } \\
\text { Operative } \\
\text { ABG(dB) }\end{array}$ & $\begin{array}{c}\text { Post } \\
\text { Operative } \\
\text { ABG(dB) }\end{array}$ & $\begin{array}{c}\text { Hearing } \\
\text { Gain(dB) }\end{array}$ & P Value \\
\hline \multirow{3}{*}{ Group A } & Mean & & & & \\
\cline { 2 - 6 } & $\begin{array}{l}\text { Standard } \\
\text { Deviation }\end{array}$ & 9.66 & 12.97 & & \\
\cline { 2 - 6 } & Minimum & 19 & 13.5 & & \\
\hline
\end{tabular}




\begin{tabular}{|l|l|c|c|c|c|}
\hline & Maximum & 55 & 52.5 & & \\
\hline \multirow{4}{*}{ Group B } & Mean & 36.79 & 25.07 & 11.72 & 0.0001 \\
\hline & Standard & 16.13051 & 13.7927 & & \\
& \begin{tabular}{l} 
Deviation \\
\cline { 2 - 6 }
\end{tabular} & & & & \\
\hline & Minimum & 15 & 10 & & \\
\hline & Maximum & 63.75 & 42 & & \\
\hline
\end{tabular}

\section{Discussion}

Chronic otitis media is a chronic infection or inflammation of the middle ear and mastoid. It is accompanied by otorrhea and hearing loss. Treatment objectives include eradication of infection and restoration of tympanic membrane and hearing. Achieving all of these parameters in COM patients is difficult and controversial. ${ }^{5,6}$ Although ear surgery has been developing quite fast in the last 20-30 years, the choice of most appropriate surgical procedure is not clear in some patients with COM. Hearing results are affected by many parameters like current otorrhea, perforation type, ossicular status, granulation tissue or cholesteatoma in the middle ear.

Canal wall up mastoidectomy or CWD mastoidectomy techniques were preferred for eradication of disease according to these changing conditions, with advantages and disadvantages of each technique..$^{7-9}$ Many prefer open cavity techniques over other techniques for common cholesteatoma, it has been stated in several studies that long-term hearing results in closed techniques are at least as successful as open techniques in treating cholesteatoma. Although recurrence has been more associated with closed cavity techniques, this risk cannot be eliminated entirely by open cavity techniques. ${ }^{10}$

Chang and Chen said they obtained better hearing results in patients with an intact stapes suprastructure. ${ }^{11}$ De Corso et al. reported that the status of middle ear mucosa and presenceor absence of stapes suprastructure are the most important factors for the successful restoration of postoperative hearing. ${ }^{12}$

Umit et al. reported that an ideal material is characterized by high biocompatibility, easy manipulation with minimal operation time and also high stability without extrusion or displacement. ${ }^{13}$

\section{Conclusion}

Canal wall down mastoidectomy with type III tympanoplasty, stapes-cartilage-graft assembly technique have more hearing improvement than stapes graft assembly technique.

\section{References}

1. Hameed A, Ahmad M, Amjad M, Shakeel A, Rizvi A. Ossicular defects in cholesteatomatous chronic suppurative otitis media. Pak Postgraduate Med J 1998;9:35-7.

2. O'Leary S, Veldman JE. Revision surgery for chronic otitis media: recurrent residual disease and hearing. $J$ laryngol Otol 2002;116(12):996-1000.
3. Cheema KM, Maqbool M, Hameed A. Surgical management of chronic suppurative otitis media. Ann 1998;4:23-4.

4. Barry E Hirsch. Ossicular chain reconstruction. In: Operative otolaryngology Head and Neck surgery. (ledn). Philadelphia. W.B. Saunders company. 1997:1262-79.

5. Sanna M, Zini C, Scandellari R, Jemmi G. Residual and recurrent cholesteatoma in closed tympanoplasty. Am J Otol 1984;5:277-82.

6. Incesulu A. Chronic suppurative otitis media. Turkiye Klinikleri J Surg Med Sci 2005;1:66-70.

7. Kartush JM. Ossicular chain reconstruction. Capitulum to malleus. Otolaryngol Clin North Am 1994;27:689-715.

8. Austin DF. Reporting results in tympanoplasty. Am J Otol 1985;6:85-8.

9. Becvarovski Z, Kartush JM. Smoking and tympanoplasty: implications for prognosis and the Middle Ear Risk Index (MERI). Laryngoscope 2001;111:1806-11.

10. Cook JA, Krishnan S, Fagan PA. Hearing results following modified radical versus canal-up mastoidectomy. Ann Otol Rhinol Laryngol 1996;105:37983.

11. Chang CC, Chen MK. Canal-wall-down tympanoplasty with mastoidectomy for advanced cholesteatoma. $J$ Otolaryngol 2000;29:270-3.

12. De Corso E, Marchese MR, Sergi B, Rigante M, Paludetti G. Role of ossiculoplasty in canal wall down tympanoplasty for middle-ear cholesteatoma: hearing results. J Laryngol Otol 2007;121:324-8.

13. Umit T, Ozgur Y, Bilgehan G, Volkan SA, Sezim SA. Results of primary ossiculoplasty and prognostic factors in canal wall-down tympanoplasty. J Craniofac Surg 2010;21:407-10. 